\title{
The Application of Bel Canto in National Vocal Music
}

\author{
Shuyue Ding \\ Mianyang Teachers' College \\ Sichuan, China 621000
}

\begin{abstract}
National vocal music is the treasure of Chinese traditional culture. It is an important bridge of our various ethnic groups. It mostly achieves the purpose of reflecting diverse singing styles by folk spread. Our national vocal music art has experienced long-term inheritance and development. It has absorbed the outstanding culture of other nations and combined with Western bel canto, which make it progress and develop constantly. China is a multi-ethnic country, and the national characteristics and origins of culture are diverse, which has laid the foundation for the diversified development of national vocal music. National vocal music represents the quintessence of Chinese culture in a sense, and also lays a solid backing for the cultural development of the country. Learning vocal music also brings a lot of joys to our life. The paper discusses the differences between the bel canto and the national vocal music, and on the basis of this, discusses the application of bel canto in national vocal music.
\end{abstract}

Keywords-Bel canto; national vocal music; application; culture

\section{COMPARISON OF BEL CANTO AND NAT IONAL VOCAL SINGING}

Bel canto originated in Italy in the 17th Century. After more than a century of development, it gradually became mature. The orig inal meaning of bel canto is goodliness in Italian, which is mainly reflected in two aspects. In singing method and vocal aesthetics similar to ours, music has no border. With hundreds of years of joint efforts of musicians around the world, the bel canto also strode over the borders. Especially it integrates well with our national vocal music. In comparison, China is composed of many ethnic groups. The language of every ethnic group has its own unique pronunciation characteristics. However, they are adapted from the presentation of some folk songs, forming a specific style. Many patterns of performance, such as, opera, rap art and national opera, appeared. It can be seen that the two are not completely contradictory. They have common points and respective characteristics. In the following the paper mainly discusses the differences of bel canto and national vocal music in order to realize the integration of bel canto and national vocal music.

\section{A. Differences in Breathing Patterns}

Breathing is the soul of singing. Although our national vocal music attaches great importance to breath way, there are no specific theoretical rules. In the folk teaching, we still use the method of mentoring teaching. This teaching mode has great limitations. Disciples mostly inherit from master, and make little changes and explorations, which isn't conducive to the in-depth study of national vocal music. In reality masters live on the unique skills, so they often have reservations to their disciples. It results in the deficiency of the inherited culture. Our vocal music lovers may have many doubts in the exploration, especially in singing pattern. Singing pattern of national vocal music is developed from chant. Perhaps we know chant of poems emphasizes the combination of breathing, poetry and emotion. The way of stressing each word reflects in singing. With deep breath, the overstress of deep breath affects the subsidence of breath. As for breathing pattern of national vocal music, it stresses to "blowup ribs and stomach and lessen lower abdomen". In other words it lifts breath by subsiding breath to abdomen. Songs singing in this method are shallow and thin, with sharp sound. As for breathing pattem of bel canto, it is particular about natural breathing which can be gotten when lying down. After long-term training, one can breathe in fully. It is very different from that of national vocal music which takes thoracic diaphragm as bearing of breath. Flexibly expand waist and abdomen, and keep the sounding state to flow breath of thoracic diaphragm downward and provide force for throat sounding. Singers mainly blowup their abdomen and lift breath by counterforce, for it can make singing sound with a sense of columnar. It sounds like a voice in the whole movement, with flexible breathing.

\section{B. Differences in Sounding Techniques}

A blend of Eastern and Western culture influences the sounding technique of our traditional vocal music, like folk opera and rap art. It collides with original ethnic region and culture, and produces the following several sounding techniques, mainly including true voice singing, false voice singing, and the combination of falsetto in treble and true force in bass. The paper mainly introduces differences of the three singing methods. True voice singing widely appears in singing songs. We usually hear singers use false voice in singing. It reflects that true voice singing accounts for the vast majority psychologically. For example singers mainly use the true voice in singing undertone of national music and folk songs. We can usually see Mongolian singers using true voice in singing Mongolian songs on TV program. Do you perceive that Mongolian uncle often sings roughly and boldly? Many people think it is related to the prairie style of 
the region. Open and large area creates this singing style. But truly it is determined by sounding technique. Sounding of treble often tests endurance capacity of throat. Many singers pursue true voice singing excessively which often overload their throat and reach a poor effect.

Falsetto singing is also an important sounding pattern in singing folk songs. In life we may feel that Sichuan dialect is characteristic which is actually falsetto. It has a strong force of penetration and toughness. Compared to simple and honest characteristic, the falsetto often gives people a thin and sharp sense and makes us nervous with relative compact pace. Before many bel canto singers pursue this specific effect. They obtain this singing effect through surgical operation. Comparatively the training method of national vocal music has seriously violated the principle of humanitarianis $\mathrm{m}$.

In addition, the combination of high-pitched falsetto singing and bass true voice singing has been widely used in the national vocal music. It is, in fact, to make up deficiencies of true voice and falsetto singing, so as to make singing more coordinated. The effective combination of their advantages can greatly improve singers' singing technique and enrich performance of music and make singing more coordinated. Now singers are using this style in singing the Northeast Folk Songs, folk songs of Mongolia and some local minors. It has both low and deep characteristics of bass and loud and clear characteristics of treble, and organically combines them together. It makes up deficiencies of singers in singing treble, and improves the technique of singers. It also enriches performance technique of music and expands sounding range and makes singing scientific. With sharp contrast of bass and treble, singers have a skillful switch of the two ways and improve the whole singing effect. But in fact, Chinese-style combination of true voice and falsetto singing is different from bel canto singing. Sometimes it even has a substantial difference. Bel canto more emphasizes the processing of voice transition region, making tone smooth and difficult to perceive the switching trace. But in singing our national vocal music, the process methods of singers are quite different. Singers often overemphasize the contradiction in switching region, forming a sharp contrast. In addition, the above three basic vocalizations also produce other singing techniques, such as, the white voice singing technique and the singing technique of language narration, which all have very unique timbres. So we can combine the unique basic sounding technique with Western advanced cultures to carry forward our national characteristics of culture better.

\section{THE APPLICAT ION METHODS OF BEL CANTO IN NATIONAL VOCAL MUSIC}

The national vocal music in bel canto can be an import part of our cultural industry. The author has an understanding of bel canto in learning music. We can make constant improvement and inherit the essence in it by fully combining ethnic languages and ethnic styles and perfectly present this art. We can learn the essence of Western singing on the basis of our national singing style, and reveal true feelings through this singing style. The paper discusses the application methods of bel canto in national vocal music from the following aspects.

\section{A. Skills Embodied in National Vocal Music}

Bel canto is a mixture of resonances. Generally it includes the upper resonance and the lower resonance. The wonderful sounds we hear are from resonances. The full and passionate voice can stimulate the soul of hearers. Singers can really sing by grasping the technique of resonance. The mixture of true and false voice in bel canto can produce a beautiful and pure sound according to certain rules. It main ly takes oral cavity, cavity head and thoracic cavity as three supporting points, so that singers can switch freely in sounding region. Signers in singing national music often express with loud and clear sound, which gives hearers a sense of both excellent in voice and affection. They often take breath in treble and use true voice in the whole process. But in fact singers slightly lift throat, reduce openness and shorten sounding tube, giving hearers a fine and smooth sense. The mixture of resonance can improve and enrich the singing techniques of national vocal music. No matter in bel canto or national singing style, singers should sing clearly. Bel canto originated in Italy. Some pronunciation rules are reflected in the form of the letter. It requires singers to sing clearly and fluently. In other word they should sing with clear articulation and a mellow and full tune. In reality some singers sing sharply and far from pleasing the ear. In order to make an improvement, we can absorb exotic advanced culture and integrate our national elements with the essence to make up deficiencies of national vocal music. The advantages of bel canto can complete it and make up deficiencies in our singing. The clear and neat expression can make our national vocal music more artistic.

\section{B. Applying the Sounding Principles of Bel Canto in National Vocal Music}

In some concerts in real life, we may find that the overtone of bel canto is winder than that of national singing. Many national singings are sharp and with obvious ups and downs. But it does not affect the aesthetic standards, as long as singers can skillfully combine language with emotions together. Singers' emotion can touch hearers. Bel canto relies on coordination of waist and abdomen in using breathing. Its mouth openness is larger, and the sound is obviously loud and clear. Just because of this, it often is not clear. But our national vocal singing can make up this deficiency. Bel canto is not popular in China. The main reason is the unclear pronunciation in singing. We can combine our national vocal music with bel canto effectively, which can keep the simple and honest characteristics of bel canto and the clear pronunciation of national vocal signing. It helps our national vocal music show its charm and makes it popular. It requires singers to grasp the sounding principles of bel canto. According to characteristics of national vocal music, singers should find the correct sounding patterns and learn from other's strong points to make up our deficiencies to make a resonance among hearers. 


\section{The Breathing of Bel Canto Used in National Vocal Music}

Breathing is important for singers. The length and frequency of breathing and the intensity of sounding affect the beauty of chorus. Many singers are different due to their special breathing patterns. So, breathing is a key link. We often hear the phase of subsiding the breath to abdomen. But this degree differs from man to man. The standards of subsiding the breath are not clear, so singers often cannot grasp it accurately. This will affect the singing effect. In this point, bel canto has its advantages. Singers use the singing principle of resonance chamber to control sound characteristics. It is easy to render the atmosphere of the stage and affect emotions of hearers.

\section{The Mutual Reference of Research Methods}

Bel canto has an inclusive research on the structure of human body. It clearly expounds the singing principles of the body parts. We lack this kind of research in national vocal music. In addition, we lack theories and have weak foundation. Music lovers generally have no direction. Sometime they may be seriously misled. Aiming at these problems, we can use bel canto research methods. Make detail explanation on parts of body and combines content of explanation with bel canto and national vocal music, focus on the positions of body parts and their functions, and coordinate application methods. It is easy for learners in the first stage to grasp it. We are a multi-ethnic group country, and all singing styles show a diverse tendency, including folk song, opera, Chinese folk arts and other art forms. The rich and colorful artistic performance forms generally meet our national aes thetic concepts, including national pronunciation characteristics and regional styles. Chinese characters in national singing highlight its beauty, and the language features of each group reflect different singing styles. For example, Mongolian songs generally give us a loud and clear sense; singing styles of Uygur mostly are lively. It is closely related to their pronunciations. So, it is considered to collect and edit pronunciations of representative ethnic groups to facilitate later researches and provide a solid foundation for the integration of Western and Eastern culture.

\section{E. Realizing the Nationalization of Bel Canto}

From the above aspects we have learned that bel canto has many advantages. On both control methods of pronunciation and singing range, it has formed a kind of standard system which has been recognized by many countries in the world. It has a long history and scientific characteristics. Many countries have regarded this as the highest level in singing expression, and some singers pursue to reach this level for lifetime. In constant development, it also attracts a large batch of domestic bel canto lovers to learn. They introduced this singing style into our country, and our people have found the differences of this singing style and national vocal music. They have made collisions in mutual reference. Especially in the period of the May 4th Movement, the combination of Chinese and western styles had been emphasized to help us make improvement. People gradually realized the similarities between these two kinds of singing styles. After adjustment of pronunciation and words in singing methods, a lot of works were showed in a combined style. But there were a lot of problems. For example, some excellent singers ever sang songs with bel canto. They sang well, but hearers often cannot hear the content clearly. The end sounds of Italian generally are vowels, while ends of Chinese are simple or compound vowels of a Chinese syllable. Therefore, it is difficult to reach the effect of clear articulation and a mellow and full tune. This problem can be solved. Most singers solve it by gradual grinding-in in training to improve fluency of breath, which makes our national vocal singing scientific and keep its national characteristics. At same time, it reflects our music lovers have spanned borders in pursuit of music. The constant reference and exchange can help realize the inheritance and development of national singing style.

\section{CONCLUSION}

Through the general understanding of bel canto and national vocal music, we know the advantages of the two singing styles. They all belong to performance. If we overemphasize the boundary of them because of their differences, it will seriously hinder the development of performing arts and the inheritance of culture. Bel canto also has both advantages and shortcomings. We shall keep our cultural connotations in national vocal music and actively learn advantages in bel canto to make up for deficiencies. The paper has discussed the differences of bel canto and national vocal music and application methods of bel canto in national vocal music. It is useful for singers to learn from foreign singing skills. By changing our training ways and singing forms, it can add diversity for our national vocal music and make further improvement. The author hopes that later scholars will not only focus on the aesthetic ele ments in appreciating the national vocal music, but also put their eyes on the international stage in order to carry forward our Chinese culture and let foreign people understand our national vocal music and Chinese stories.

\section{REFERENCES}

[1] Ma Di. Comparison of Emotional Expressions and Singing Skills of National Vocal Music and Bel Canto. Journal of Henan Normal University (PHILOSOPHY AND SOCIAL SCIENCE EDITION), 2008, 35 (5): 261-262.

[2] Pang Jie. Influence of the Spread of Bel Canto on National Vocal Music in China. Drama Family, 2015, (5): 77-78.

[3] Wu Qin. How to Carry Forward the Nationalization of National Vocal Music and Move towards the World under the Influence of Bel Canto. Education and Teaching Forum, 2016, (41): 146-149. 